\title{
Concentrations of resveratrol and derivatives in foods and estimation of dietary intake in a Spanish population: European Prospective Investigation into Cancer and Nutrition (EPIC)-Spain cohort
}

Raul Zamora-Ros ${ }^{1}$, Cristina Andres-Lacueva ${ }^{1}$, Rosa M. Lamuela-Raventós ${ }^{1}$, Toni Berenguer ${ }^{2}$, Paula Jakszyn ${ }^{2}$, Carmen Martínez ${ }^{3}$, María J. Sánchez ${ }^{3}$, Carmen Navarro ${ }^{4}$, María D. Chirlaque ${ }^{4}$, María-José Tormo ${ }^{4}$, Jose R. Quirós ${ }^{5}$, Pilar Amiano ${ }^{6}$, Miren Dorronsoro ${ }^{6}$, Nerea Larrañaga ${ }^{6}$, Aurelio Barricarte ${ }^{7}$, Eva Ardanaz ${ }^{7}$ and Carlos A. González ${ }^{2}$

${ }^{1}$ Nutrition and Food Science Department, XaRTA, INSA, Pharmacy School, University of Barcelona, Av. Joan XXIII, s/n. 08028, Barcelona, Spain

${ }^{2}$ Unit of Epidemiology, Catalan Institute of Oncology, Institute of Biomedical Research of Bellvitge, L'Hospitalet de Llobregat, Spain

${ }^{3}$ Andalusian School of Public Health, Granada, Spain

${ }^{4}$ Servicio de Epidemiología, Consejería de Sanidad, Murcia, Spain

${ }^{5}$ Consejería de Sanidad y Servicios Sociales de Asturias, Oviedo, Spain

${ }^{6}$ Dirección de Salud de Guipúzcoa, San Sebastián, Spain

${ }^{7}$ Instituto de Salud Pública de Navarra, Pamplona, Spain

(Received 12 September 2007 - Revised 25 October 2007 - Accepted 6 November 2007 - First published online 21 December 2007)

Resveratrol has been shown to have beneficial effects on diseases related to oxidant and/or inflammatory processes and extends the lifespan of simple organisms including rodents. The objective of the present study was to estimate the dietary intake of resveratrol and piceid (R\&P) present in foods, and to identify the principal dietary sources of these compounds in the Spanish adult population. For this purpose, a food composition database (FCDB) of R\&P in Spanish foods was compiled. The study included 40685 subjects aged 35-64 years from northern and southern regions of Spain who were included in the European Prospective Investigation into Cancer and Nutrition (EPIC)-Spain cohort. Usual food intake was assessed by personal interviews using a computerised version of a validated diet history method. An FCDB with 160 items was compiled. The estimated median and mean of R\&P intake were 100 and $933 \mu \mathrm{g} / \mathrm{d}$ respectively. Approximately, $32 \%$ of the population did not consume R\&P. The most abundant of the four stilbenes studied was trans-piceid (53.6\%), followed by trans-resveratrol (20.9\%), cis-piceid (19.3\%) and cis-resveratrol (6.2\%). The most important source of R\&P was wines $(98.4 \%)$ and grape and grape juices (1.6\%), whereas peanuts, pistachios and berries contributed to less than $0.01 \%$. For this reason the pattern of intake of R\&P was similar to the wine pattern. This is the first time that R\&P intake has been estimated in a Mediterranean country.

Resveratrol: Food composition databases: Intake: Wine: European Prospective Investigation into Cancer and Nutrition (EPIC)-Spain

Resveratrol (3,5, $4^{\prime}$-trihydroxystilbene) is the parent compound of a family of molecules, including glycosides (piceid) and polymers (viniferins), existing in cis and trans configurations classified as stilbenes ${ }^{(1)}$. The essential structural skeleton comprises two aromatic rings linked by a methylene bridge (Fig. 1).

Resveratrol and piceid (R\&P) are mainly present in grape and wine derivatives and their composition is affected by grape cultivar, degree of maturity at harvest, fungal pressure, climate and wine-making technology ${ }^{(2,3)}$. Secondary food sources of stilbenes are peanuts, pistachios and berries ${ }^{(4-7)}$. Recently R\&P were also detected in the skin of tomatoes, although the concentrations are 3000 times lower than those found in red table grapes, and $\mathrm{R} \& \mathrm{P}$ have not been found in all kinds of tomato ${ }^{(8)}$. The importance of R\&P food sources depends on food composition and the amount of consumption of them (standard serving size: grapes, $150 \mathrm{~g}$; wine, $125 \mathrm{ml}$; berries and peanuts, $30 \mathrm{~g}$ ). The total qualitative and quantitative $\mathrm{R} \& \mathrm{P}$ profile is also affected by the source: trans-piceid is mainly present in red and white wines and grape juice; cispiceid in rosé and sparkling wines and trans-resveratrol in grapes, berries, peanuts and pistachios ${ }^{(4-7,9-11)}$. Until now, viniferins have only been described in grape derivatives ${ }^{(12,13)}$.

Resveratrol is of great interest in nutrition and medicine due to its potential health benefits, such as anti-carcinogenic ${ }^{(14,15)}$, neuroprotector $^{(16)}$ and antioxidant effects ${ }^{(17)}$, as a modulator

Abbreviations: EPIC, European Prospective Investigation into Cancer and Nutrition; FCDB, food composition database; R\&P, resveratrol and piceid.

* Corresponding author: Dr Cristina Andrés-Lacueva, fax +34 9340359 31, email candres@ub.edu 


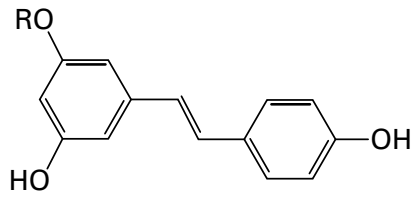

(a) $\mathrm{R}=\mathrm{OH}$

(c) $\mathrm{R}=$ glucose

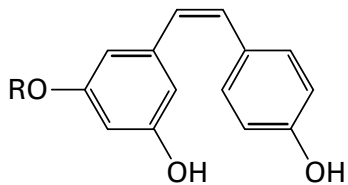

(b) $\mathrm{R}=\mathrm{OH}$

(d) $\mathrm{R}=$ glucose
Fig. 1. Structures of resveratrol and derivatives: (a) trans-resveratrol; (b) cisresveratrol; (c) trans-piceid; (d) cis-piceid.

of lipid and lipoprotein metabolism, as an antiplatelet aggregator $^{(18)}$ and its oestrogenic activity ${ }^{(19)}$. Indeed, it has been hypothesised that resveratrol uses the same pathways activated by energy restriction ${ }^{(20-22)}$. The biological effects have been studied mainly in vitro, although there is also growing in vivo evidence $^{(20)}$. Some effects required a high concentration of resveratrol in tissues, although chemopreventive and chemotherapeutic anticancer effects are an exception ${ }^{(14,15)}$. In this case, resveratrol, at micromolar concentrations, affects the activity of transcriptional factors involved in proliferation and stress responses and leads to the modulation of survival and apoptotic factors in carcinogenesis ${ }^{(14,15)}$. In atherosclerotic and neurodegenerative diseases, the effects of resveratrol are not only due to its antioxidant and scavenging activities, but also to its participation in the modulation of signal transduction pathways and in the activation of several enzymes at micromolar concentrations ${ }^{(14,23,24)}$.

The pharmacological effects are consistent with the resveratrol concentration in plasma, LDL and urine after oral administration in human subjects ${ }^{(25-32)}$. The biological effect of resveratrol will ultimately depend on the cellular effects of the circulating metabolites that are effectively absorbed (glucuronides and sulfates) ${ }^{(30)}$ and not on the native forms in food $^{(33,34)}$. However, other authors have speculated that resveratrol metabolites may become deconjugated at the target sites of action, thereby releasing aglycone to elicit biological activity ${ }^{(15,35)}$.

Intake values of trans- and cis-resveratrol and piceids are not available either since there is no complete food composition database (FCDB) of R\&P. The aim of the present study was to compile composition data of R\&P in common Spanish foods and to evaluate major food sources and their daily intake in the Spanish adult population.

\section{Materials and methods}

\section{Population}

Dietary data and other lifestyle factors from 41440 subjects, aged 29-69 years, who participated in the European Prospective Investigation into Cancer and Nutrition (EPIC) in Spain, were studied. Participants were healthy volunteers, blood donors principally, recruited between October 1992 and July 1996 in five Spanish regions: three from the North (Asturias, Navarra and Gipuzkoa) and two from the South (Murcia and Granada) ${ }^{(36)}$. After the exclusion of 755 subjects because of implausible dietary information, the final population studied consisted of 40885 subjects (15448 men and 25237 women) aged 35-64 years. The mean ages at recruitment were 50.8 and 48.4 years for men and women, respectively.

\section{Dietary information}

Usual food intake during the preceding year, taking into account seasonal variations, was estimated by personal interview using a computerised diet history questionnaire. This was developed and validated specifically for the EPIC study in Spain ${ }^{(37,38)}$. The questionnaire was structured according to occasion of food intake (breakfast, lunch, dinner). Trained interviewers gathered data on preparation method, average frequency of consumption per week, and usual portion size for each food consumed at least twice per month (or once per month for seasonal foods). Portion sizes were reported in natural units, household measures or with the aid of a manual of thirty-five sets of photographs prepared specifically for the study. The questionnaire included a list of more than 600 foods and beverages and about 150 regional recipes. For each food described, the final amount consumed was calculated, taking into account the cooking method used and the edible part consumed.

\section{Food composition database}

A literature search was conducted in MEDLINE (United States National Library of Medicine, 2006) and in the Food Science and Technology Abstracts (International Food Information Service, 2006) to identify sources of resveratrol compounds in Spanish foods in published food composition data. The search terms included resveratrol, piceid, food composition, food, wine, berry, peanuts, pistachios and tomato. Review papers that did not contain new primary data were excluded. However, the citations used in these reviews were cross-checked with initial literature searching to identify any additional references.

The following information was extracted from each publication: (1) food information: name, food description, scientific name and country of the study; (2) measurement information: value, type of value (mean, median, range, other), number of samples, sampling method and analytical method; (3) bibliographic reference. With this information we assessed the data quality for inclusion in the Database following the key points originally developed in the EU-AIR NETTOX Project ${ }^{(39)}$.

The appropriate methods of analysis were HPLC diode array or GC/MS. When cis- and trans-piceid were quantified by spectrophotometric method and were expressed as resveratrol, conversion factors were applied: $\times 1.57$ and $\times 1.75$ for trans- and cis-piceid, respectively. These factors were calculated using the relationship between the molar absorptivities of trans-resveratrol (UV $\lambda$ (10\% ethanol) nm (ع) 306 (31 800/ $\mathrm{M} / \mathrm{cm}))^{(40)}$ and trans-piceid (UV $\lambda(10 \%$ ethanol) $\mathrm{nm}(\varepsilon) 306$ (20 100/M/cm)) (R Zamora-Ros et al., unpublished results), and the relationship between cis-resveratrol (UV $\lambda$ (10\% ethanol) $\mathrm{nm}(\varepsilon) 286(13100 / \mathrm{M} / \mathrm{cm}))^{(40)}$ and cis-piceid (UV $\lambda$ $(10 \%$ ethanol) $\mathrm{nm}(\varepsilon) 286(7500 / \mathrm{M} / \mathrm{cm}))$ (R Zamora-Ros et al., unpublished results), respectively.

Units of measurements and modes of expression varied across the studies. To standardise, values were converted into $\mathrm{mg} / 100 \mathrm{~g}$ fresh weight. Data for similar foods were aggregated as weighted means, taking into account the number of samples, sampling plan and frequency of consumption of Spanish foods ${ }^{(41)}$.

When we did not find Spanish food values for important sources of resveratrol such as peanuts, pistachios or berries we selected foreign food values. Other unknown values were estimated using a biologically similar food or calculating 
recipes. Despite the use of other countries' and estimated values, data were still not available for some foods.

\section{Statistical analyses}

Distributions were expressed as means, standard deviations, medians, and as 25 th and 75 th percentiles, and were measured separately for men and women. Because R\&P intakes were skewed toward higher values, we used median values to compare results. The average estimates of dietary intakes were standardised by sex and age of the Spanish population aged 35-64 years ${ }^{(42)}$. The contribution of each food to the total intake of individual and total $\mathrm{R} \& \mathrm{P}$ was calculated as a percentage.

To assess the differences in $\mathrm{R} \& \mathrm{P}$ intake with respect to the categories of age, region, educational level, tobacco smoking, BMI and energy intake, estimations of the proportion of consumers and R\&P median intake among consumers were calculated using linear regression analysis, respectively. All these models were adjusted by sex, age, region, BMI and energy intake $(\mathrm{kJ} / \mathrm{d})$. To perform the linear regression analysis, a Box-Cox transformation of the response variable was necessary to observe the assumptions of the model, and the inverse transformation was applied to the resulting estimates to interpret them as medians ${ }^{(43)}$. Data were analysed with the $\mathrm{R}$ language and environment for statistical computing and graphics ${ }^{(44)}$.

\section{Results}

\section{Food composition database}

Resveratrol values from fifty-four studies were used to compile the final food database. The compilation included 160 food items with information on the concentrations of transand cis-resveratrol, trans- and cis-piceid and sum of R\&P. Table 1 summarises the resveratrol content from all references compiled for all the common Spanish foods considered. Red wine $(0.847 \mathrm{mg} / 100 \mathrm{~g})$ and itadori tea $(0.974 \mathrm{mg} / 100 \mathrm{~g})$ were the highest sources of R\&P, but itadori tea is not consumed in Spain. Intermediate sources of R\&P $(0.08-0.547 \mathrm{mg} / 100 \mathrm{~g})$ corresponded to other kinds of wine, grapes, grape juice and peanut butter. Lowest sources of $R \& P(<0.01 \mathrm{mg} / 100 \mathrm{~g})$ were peanuts, pistachios and berries.

\section{Estimated resveratrol intake}

Table 2 shows the mean and median values and percentiles of trans- and cis-resveratrol, trans- and cis-piceid and total reveratrol intake by sex in the studied population. Average intake of $\mathrm{R} \& \mathrm{P}$ was $933 \mu \mathrm{g} / \mathrm{d}$, with a median of $100 \mu \mathrm{g} / \mathrm{d}$. As indicated by the median and percentiles, the distribution was skewed to higher values. A total of 13175 participants (39.0 and $20.0 \%$ of total women and men standardised by sex and age of the Spanish population respectively) had a total resveratrol intake of $0 \mu \mathrm{g} / \mathrm{d}$ (non-consumers). trans-Piceid contributed $53.7 \%$ of total resveratrol intake, trans-resveratrol $20.8 \%$, cis-piceid $19.3 \%$ and cis-resveratrol $6.2 \%$.

Table 3 shows the differences in R\&P intake according to sex, age, geographic area, energy intake, BMI, education and tobacco smoking. Medians and percentages of consumers were adjusted by sex, age, BMI, region and energy consumption. $\mathrm{R} \& \mathrm{P}$ consumption was lower in quantity and percentage of women consumers $(137 \mu \mathrm{g} / \mathrm{d}$ and $61.0 \%)$ than in men $(686 \mu \mathrm{g} / \mathrm{d}$ and $80.0 \%)$. Mean of R\&P and percentage of

Table 1. Food composition data sources for resveratrol content (mg/100 g fresh weight)

\begin{tabular}{|c|c|c|c|c|c|c|}
\hline Food item & $\begin{array}{l}\text { trans- } \\
\text { resveratrol }\end{array}$ & $\begin{array}{l}\text { cis- } \\
\text { resveratrol }\end{array}$ & $\begin{array}{l}\text { trans- } \\
\text { piceid }\end{array}$ & $\begin{array}{l}\text { cis- } \\
\text { piceid }\end{array}$ & $\begin{array}{l}\text { Total } \\
\text { resveratrol }\end{array}$ & References \\
\hline $\begin{array}{l}\text { Wine, not } \\
\text { specified }\end{array}$ & 0.114 & 0.037 & 0.303 & 0.105 & 0.558 & Calculated* \\
\hline Red wine & $0 \cdot 181$ & 0.044 & 0.495 & 0.127 & 0.847 & $\begin{array}{l}\text { Lamuela-Raventós et al. }{ }^{(10)} \text {, Moreno-Labanda et al. }{ }^{(46)} \text {, } \\
\text { Goldberg et al. }{ }^{(60)} \text {, Rodriguez-Delgado et al. }{ }^{(61)}\end{array}$ \\
\hline Rosé wine & 0.041 & 0.041 & 0.071 & 0.154 & 0.307 & Romero Perez et al. ${ }^{(11)}$ \\
\hline White wine & 0.010 & 0.016 & $0 \cdot 26$ & 0.022 & 0.074 & $\begin{array}{l}\text { Romero Perez et al. }{ }^{(11)} \text {, Rodriguez-Delgado et al. }{ }^{(61)} \text {, } \\
\quad \text { Álvarez-Sala et al. }{ }^{(62)} \text {, Martinez-Ortega et al. }{ }^{(63)}\end{array}$ \\
\hline Sparkling wine & 0.005 & 0.014 & 0.018 & 0.055 & 0.092 & Andres-Lacueva et al. ${ }^{(64)}$, Pozo-Bayon et al. ${ }^{(65)}$ \\
\hline Fortified wine & 0.110 & 0.095 & 0.141 & 0.040 & 0.386 & de Lima et al. ${ }^{(66)}$, Goldberg et al. ${ }^{(67)}$ \\
\hline $\begin{array}{l}\text { Grapes, not } \\
\text { specified }\end{array}$ & $0 \cdot 156$ & - & 0.067 & - & 0.223 & Cantos et al. ${ }^{(9,68,69)}$ \\
\hline Red grapes & 0.250 & $\operatorname{tr}$ & 0.060 & - & 0.310 & Cantos et al. ${ }^{(9,68,69)}$ \\
\hline White grapes & 0.068 & $\operatorname{tr}$ & 0.025 & - & 0.093 & Cantos et al. ${ }^{(9,68)}$ \\
\hline Must & 0.070 & 0.012 & 0.465 & - & 0.547 & Vinas et al. ${ }^{(70)}$ \\
\hline Grape juice & 0.010 & $\operatorname{tr}$ & 0.036 & 0.043 & 0.088 & Martinez-Ortega et al. ${ }^{(63)}$, Roldan et al. ${ }^{(71)}$, Romero-Perez et al. ${ }^{(72)}$ \\
\hline $\begin{array}{l}\text { Peanuts, } \\
\text { toasted }\end{array}$ & 0.006 & - & - & - & 0.006 & Sobolev \& Cole ${ }^{(6)}$, Lee et al. ${ }^{(47)}$ \\
\hline $\begin{array}{l}\text { Pistachios, } \\
\text { toasted }\end{array}$ & 0.007 & - & - & - & 0.007 & Tokusoglu et al. ${ }^{(7)}$ \\
\hline Peanut butter & 0.065 & nd & 0.014 & nd & 0.080 & Ibern-Gomez et al. ${ }^{(73)}$ \\
\hline Cranberry juice & $\operatorname{tr}$ & - & - & - & $\operatorname{tr}$ & Zhang \& Zuo ${ }^{(74)}$ \\
\hline Berries $\ddagger$ & 0.008 & - & - & - & 0.008 & Rimando et al. ${ }^{(5)}$, Lyons et al. ${ }^{(75)}$ \\
\hline $\begin{array}{l}\text { Itadori tea } \\
\quad \text { (infusion) }\end{array}$ & 0.068 & nd & 0.906 & nd & 0.974 & Burns et al. ${ }^{(4)}$ \\
\hline
\end{tabular}

tr, Traces; nd, not detected.

${ }^{*}$ Calculated from consumption of Spanish population: $57 \%$ red wine, $25 \%$ white wine and $18 \%$ rosé wine.

† Recipe of sangria (typical Spanish beverage): $50 \%$ of red wine and $50 \%$ of orange juice, fruit mix (peaches, oranges, lemons, etc.) and sugar.

$\ddagger$ Berries included: blueberry, bilberry, sparkleberry, deerberry, cranberry, lingonberry and partridgeberry. 
Table 2. Estimated resveratrol intake $(\mu \mathrm{g} / \mathrm{d})$ in the European Prospective Investigation into Cancer and Nutrition (EPIC)Spain by sex

\begin{tabular}{|c|c|c|c|c|c|}
\hline & trans-resveratrol* $^{*}$ & cis-resveratrol $^{\star}$ & trans-piceid $^{*}$ & cis-piceid* & Total resveratrol $^{*}$ \\
\hline \multicolumn{6}{|l|}{ Men (n 15 448) } \\
\hline Mean & 337 & 101 & 878 & 313 & 1629 \\
\hline SD & 442 & 121 & 1213 & 380 & 2076 \\
\hline Median & 165 & 61 & 356 & 181 & 902 \\
\hline Percentiles, 25th-75th & $14-502$ & $0-162$ & $14-1309$ & $4-497$ & $48-2504$ \\
\hline \multicolumn{6}{|l|}{ Women (n 25 237) } \\
\hline Mean & 51 & 15 & 123 & 46 & 235 \\
\hline SD & 121 & 35 & 325 & 111 & 571 \\
\hline Median & 0 & 0 & 0 & 0 & 0 \\
\hline Percentiles, 25th -75 th & $0-42$ & $0-9$ & $0-56$ & $0-27$ & $0-148$ \\
\hline \multicolumn{6}{|l|}{ Total ( $n 40685)$} \\
\hline Mean & 194 & 58 & 501 & 180 & 933 \\
\hline SD & 354 & 99 & 965 & 310 & 1675 \\
\hline Median & 31 & 5 & 36 & 16 & 100 \\
\hline Percentiles, 25th-75th & $0-228$ & $0-81$ & $0-545$ & $0-246$ & $0-1219$ \\
\hline
\end{tabular}

${ }^{*}$ Adjusted by sex and age of Spanish population aged 35-64 years.

consumers tended to increase in the older age categories. Individuals from the northern regions consumed more resveratrol than from the southern regions (513 $v .125 \mu \mathrm{g} / \mathrm{d}$ ), although the percentage of consumers was approximately the same $(88.3 v$. $69.4 \%$ ). Increasing intake of $\mathrm{R} \& \mathrm{P}$ and percentage of consumers seemed to be correlated with higher energy intake. Individuals with a BMI between 25 and $30 \mathrm{~kg} / \mathrm{m}^{2}$ had the highest intake of total resveratrol $(333 \mu \mathrm{g} / \mathrm{d})$ and the obese group had the smallest percentage of consumers $(66.3 \%)$. Individuals with a high level of education (technical and professional, secondary school or university degree) had a higher intake of $\mathrm{R} \& \mathrm{P}$ than those with only primary education or no education (340-346 v. 298-308 $\mu \mathrm{g} / \mathrm{d}$ ), and the proportion of consumers was also higher in this group $(69 \cdot 8-72.4 \%$ v. $68 \cdot 0-68.6 \%)$. There was a decrease in R\&P intake and percentage of consumers in non-smokers $(259 \mu \mathrm{g} / \mathrm{d}$ and $67.1 \%)$ when compared with current $(369 \mu \mathrm{g} / \mathrm{d}$ and $71.0 \%)$ and former smokers (342 $\mu \mathrm{g} / \mathrm{d}$ and $69.4 \%$ ).

\section{Sources of resveratrol}

Table 4 shows the major contributors to R\&P intake. The richest source was red wine $(82.6 \%)$. As grouped foods, the main contributors were wines $(98.4 \%)$, grapes $(1.1 \%)$, must and juices $(0.5 \%)$ and, finally, peanuts and pistachios $(<0.01 \%)$. For trans-piceid, the major contributors were wines $(98.7 \%)$, must and juices $(0.7 \%)$ and grapes $(0.6 \%)$. For trans-resveratrol, we identified the following food items: wines $(95.9 \%)$, grapes $(3.8 \%)$, must and juices $(0.3 \%)$ and peanuts, pistachios and berries $(0.03 \%)$. For cis-isomers, we observed the next ranking: wines (99.9 and 99.7\%) and must and juices $(0.1$ and $0.3 \%)$ for cis-resveratrol and cispiceid, respectively.

\section{Discussion}

The present study represents the first attempt to compile the available literature for $\mathrm{R} \& \mathrm{P}$ in common Spanish foods. After developing an FCDB, we estimated dietary intakes and food sources of R\&P in Spanish adults.
Previous papers have compared results of the trans-resveratrol content but have not compiled data from trans- and cis-piceid and cis-resveratrol ${ }^{(4,20)}$. R\&P are characteristic components of Vitis vinifera $\mathrm{L}$. and are present in grape derivatives. $\mathrm{R} \& \mathrm{P}$ is not unique to Vitis because it is also present in at least seventy-two other plant species ${ }^{(45)}$, but only berries, peanuts and pistachios are components of the human diet. The high variability in $\mathrm{R} \& \mathrm{P}$ food composition, red wines ranged between $2 \cdot 86^{(10)}$ and $32.33 \mathrm{mg} R \& \mathrm{P}$ per $100 \mathrm{ml}^{(46)}$, was solved with weighted means, adjusted according to Spanish food consumption ${ }^{(41)}$. Another consideration in the FCDB was the potential losses in R\&P from foods during cooking. The data available from the study by Lee et al. ${ }^{(47)}$ suggest that average losses during toasting peanuts are approximately $30 \%$. The most common method for the measurement of R\&P is HPLC coupled to a UV detector. Until 2004-5, due to the non-availability of a commercial standard, the piceid results were expressed as equivalents of resveratrol, underestimating 1.57 - and 1.75-fold for transand cis-piceid, respectively. We, therefore, applied a correction factor to minimise this error. FCDB also reported a quality index for each value to guarantee the individual quality data and the global control of FCDB. However, further investigation is required to analyse new sources of $R \& P$, because to date many foods have not yet been studied. In a recent study, $\mathrm{R} \& \mathrm{P}$ were found in the tomato skin, but in very small concentrations $(0-18.4 \text { parts per million of dried tomato skin })^{(8)}$. This value was not used in this FCDB because not all kinds of tomato contain R\&P, the concentration is very low (3000 times lower than in red table grape skin) and, at this moment, only one paper reported this compound in American varieties of tomato $^{(8)}$ and not in European varieties ${ }^{(48)}$.

The median and the mean of the estimated daily intake of $\mathrm{R} \& \mathrm{P}$ were 100 and $933 \mu \mathrm{g} / \mathrm{d}$ respectively, and were standardised according to the age and sex structure of the Spanish population aged 35-64 years. The median of intake was significantly higher in males, in oldest age, current smokers, highest educational levels, Northern region and highest energy intake. The large discrepancies between the mean and median values were due to the fact that more than $32 \%$ of the participants did not consume R\&P, and there was a 
Table 3. Estimated intake $(\mu \mathrm{g} / \mathrm{d})$ and percentage of consumers of total resveratrol in the European Prospective Investigation into Cancer and Nutrition (EPIC)-Spain cohort by age and selected demographic and lifestyle factors*

\begin{tabular}{|c|c|c|c|c|c|c|c|c|}
\hline & Subjects $(n)$ & Consumers (\%) & Adjusted (\%) & Percentage lower $95 \%$ & Percentage upper $95 \%$ & Median adjusted & Lower $95 \%$ & Upper $95 \%$ \\
\hline \multicolumn{9}{|l|}{ Sex } \\
\hline Female & 25237 & $57 \cdot 1$ & $61 \cdot 0$ & $60 \cdot 3$ & $61 \cdot 8$ & 137 & 131 & 144 \\
\hline Male & 15448 & 84.7 & 80.0 & 79.0 & 88.9 & 686 & 664 & 709 \\
\hline \multicolumn{9}{|l|}{ Age (years) } \\
\hline $35-44$ & 13877 & 65.7 & $67 \cdot 3$ & $66 \cdot 3$ & $68 \cdot 3$ & 271 & 259 & 283 \\
\hline $45-54$ & 16107 & $68 \cdot 8$ & 69.5 & 68.7 & 70.4 & 324 & 312 & 336 \\
\hline $55-64$ & 10701 & 68.2 & $70 \cdot 8$ & 69.8 & 71.9 & 365 & 349 & 382 \\
\hline \multicolumn{9}{|l|}{ Region } \\
\hline North Spain & 24752 & 69.5 & $68 \cdot 3$ & 67.5 & 69.0 & 513 & 498 & 528 \\
\hline South Spain & 15933 & $64 \cdot 8$ & 69.4 & 68.5 & $70 \cdot 3$ & 125 & 119 & 131 \\
\hline \multicolumn{9}{|l|}{ Energy intake $(\mathrm{kJ} / \mathrm{d})$} \\
\hline Q1 (1350-6900) & 8137 & 45.6 & 53.2 & 51.4 & 55.0 & 130 & 115 & 146 \\
\hline Q2 (6900-8410) & 8137 & 59.2 & 63.7 & $62 \cdot 4$ & 65.0 & 202 & 189 & 217 \\
\hline Q3 (8410-9960) & 8137 & $69 \cdot 1$ & $70 \cdot 6$ & 69.5 & 71.7 & 266 & 253 & 280 \\
\hline Q4 (9960-12050) & 8137 & 77.4 & 74.9 & 73.9 & $76 \cdot 0$ & 375 & 357 & 392 \\
\hline Q5 (12050-42680) & 8137 & 86.8 & $79 \cdot 8$ & 78.5 & $81 \cdot 0$ & 520 & 492 & 550 \\
\hline \multicolumn{9}{|l|}{ BMI $\left(\mathrm{kg} / \mathrm{m}^{2}\right) \dagger$} \\
\hline$<25$ & 8965 & 67.7 & 70.5 & 69.2 & $71 \cdot 7$ & 298 & 281 & 317 \\
\hline $25-30$ & 19390 & 70.5 & $70 \cdot 2$ & 69.4 & 71.0 & 333 & 321 & 346 \\
\hline$>30$ & 12219 & 63.0 & $66 \cdot 3$ & $65 \cdot 2$ & $67 \cdot 3$ & 296 & 281 & 311 \\
\hline \multicolumn{9}{|l|}{ Highest school level† } \\
\hline None & 13936 & 64.0 & $68 \cdot 0$ & 66.9 & 69.0 & 298 & 283 & 313 \\
\hline Primary completed & 15846 & 67.2 & $68 \cdot 6$ & 67.6 & 69.5 & 308 & 296 & 321 \\
\hline Technical/professional & 3344 & $77 \cdot 2$ & $72 \cdot 4$ & 70.4 & $74 \cdot 3$ & 345 & 314 & 378 \\
\hline Secondary school & 2611 & $70 \cdot 1$ & 69.8 & 67.8 & 71.8 & 346 & 313 & 381 \\
\hline University degree & 4674 & $72 \cdot 3$ & $72 \cdot 0$ & 70.5 & 73.6 & 340 & 315 & 365 \\
\hline \multicolumn{9}{|l|}{ Smoking status $\dagger$} \\
\hline Former smoker & 7180 & 75.7 & 69.4 & $68 \cdot 1$ & $70 \cdot 8$ & 342 & 324 & 360 \\
\hline Current smoker & 9951 & $74 \cdot 2$ & $71 \cdot 0$ & 69.9 & $72 \cdot 1$ & 369 & 352 & 387 \\
\hline Never a smoker & 22558 & 61.2 & 67.1 & $66 \cdot 3$ & 67.9 & 259 & 249 & 269 \\
\hline
\end{tabular}

Adjusted by age and sex of Spanish population aged 35-64 years; differences between categories for all variables $P<0.001$

†The values reported are calculated by the number of subjects with valid information. The number of subjects with missing information was as follows: BMI, $n$ 111; highest school level, $n 274$; smoking status, $n$ 996. 
Table 4. Consumption of total resveratrol in the European Prospective Investigation into Cancer and Nutrition (EPIC)-Spain cohort by food items

\begin{tabular}{lcc}
\hline Food item & $\begin{array}{c}\text { Proportion of } \\
\text { intake (\%) }\end{array}$ & $\begin{array}{c}\text { Cumulative } \\
\text { percentage }\end{array}$ \\
\hline Red wine & 82.63 & 82.63 \\
Rosé wine & 12.19 & 94.83 \\
Wine, not specified & 2.92 & 97.75 \\
Grapes, not specified & 1.13 & 98.88 \\
Must & 0.39 & 99.27 \\
White wine & 0.29 & 99.56 \\
Vermouth & 0.21 & 99.77 \\
Fruit juice & 0.11 & 99.88 \\
Sparkling wine & 0.05 & 99.93 \\
Fortified wine & 0.04 & 99.97 \\
Txacoli (typical Basque wine) & 0.02 & 99.99 \\
Sherry wine & $<0.01$ & 99.99 \\
Peanuts, toasted & $<0.01$ & 99.99 \\
Pistachio, toasted & $<0.01$ & 100 \\
\hline
\end{tabular}

skewed distribution toward higher values in the consumers. This distribution of R\&P intake was similar to that of wine, because more than $98 \%$ of $\mathrm{R} \& \mathrm{P}$ intake was due to wine. The pattern of wine consumption in the EPIC European cohort was described by Sieri et al. ${ }^{(49)}$. A typical high wine consumer, and consequently high R\&P consumer, was an older man, a resident of northern Spain, with a high educational level, smoker, with excess weight but not obese and a high energy intake ${ }^{(49,50)}$. In Spain, as in Portugal, the pattern of alcohol consumption is changing: the prevalence of wine drinkers is decreasing, and younger generations are shifting from wine to beer and spirits ${ }^{(51)}$.

To our knowledge, only one case-control study estimated trans-resveratrol intake for women in the Swiss Canton of Vaud $^{(52)}$. One limitation to comparison of the results is that Levi et al. ${ }^{(52)}$ did not include a complete description, only reporting tertiles. On the other hand, they only used grapes and white and red wine, without taking into account other sources of trans-resveratrol such as grape juice, other kinds of wine, peanuts, berries, etc. Taking into account that trans-resveratrol only corresponded to $21 \%$ of the four stilbenes investigated in the present study, the median of intake of total individuals was $31 \mu \mathrm{g} / \mathrm{d}(0 \mu \mathrm{g} / \mathrm{d}$ for women), and the sources of R\&P were $29 \mu \mathrm{g} / \mathrm{d}$ for wine $(98.3 \%)$ and $0.5 \mu \mathrm{g} / \mathrm{d}$ for grapes $(1.2 \%)$. However, in the study by Levi et al. the distribution in food sources was very different, because the second tertiles for wine and grapes were $0 \cdot 1-176 \cdot 8 \mu \mathrm{g} / \mathrm{d}$ and $72 \cdot 3-126 \cdot 4 \mu \mathrm{g} / \mathrm{d}$, respectively ${ }^{(52)}$. This great difference in resveratrol intake from grapes can be due to using other food composition data. Furthermore, in populations with other dietary patterns, the contribution of berries and peanut butter may be different.

In human subjects, the proportion of nutritional resveratrol absorbed ranged from 16 to $25 \%$ of intake, measured in urine by MS techniques ${ }^{(25,27)}$. Piceid may be absorbed directly, as reported for the rat small intestine ${ }^{(53)}$, and/or hydrolysed by glycosidases before absorption ${ }^{(54)}$, contributing to the biologically available resveratrol dose. Biomarkers of resveratrol intake, such as urinary resveratrol metabolites, can be used as an alternative to evaluate resveratrol status and to assess relationships between resveratrol and disease ${ }^{(32)}$.
The use of biomarkers avoids problems associated with an $\mathrm{FCDB}^{(55)}$. In a recent study, resveratrol metabolites in urine were used as a biomarker of moderate wine consumption in intervention and epidemiological studies ${ }^{(32)}$. However, not all epidemiological studies are able to undertake the measurement of biomarkers due to a lack of resources or expertise. For this reason, estimation of resveratrol intake from dietary questionnaires and records using adequate food composition data is also required ${ }^{(56)}$.

$\mathrm{R} \& \mathrm{P}$ have been shown to have health benefits in in vitro studies, and against cancer, cardiovascular and neurodegenerative diseases. Levi et al. found a significant inverse association between trans-resveratrol and breast cancer from grapes (OR 0.64 and 0.55 ) but not from wine ${ }^{(52)}$. Polyphenols in wine may play an active role in limiting the initiation and progression of atherosclerosis ${ }^{(57)}$. Localised accumulation of resveratrol in epithelial cells along the aerodigestive tract, and potentially active resveratrol metabolites, may also produce cardiovascular effects. Moreover, resveratrol has been considered to be a energy restriction mimetic in vitro and in lower organisms and mice, because it interacts with a variety of enzymes, such as sirtuin, involved in regulating stress responses and longevity ${ }^{(20-23)}$. So, long-term consumption of a low concentration of polyphenol, such as resveratrol, or a synergic effect with other phenolic compounds or other micronutrients in the Mediterranean diet could be sufficient to cause beneficial effects against these alterations and could constitute a potential arm for prevention of chronic diseases and new therapeutic strategies ${ }^{(23)}$. It is, therefore, of interest to study the relationship between R\&P intake and the risk of chronic diseases in an epidemiological context. However, wine polyphenols are a complex mixture of flavonoids and non-flavonoids (where resveratrol would be included) and the relative contribution of each single one or synergistic contribution of them is still unclear and further investigation should be considered.

One limitation of the present study was that the EPIC-Spain cohort is based on a non-representative sample of the general population. However, the number of volunteers was very large, the participation rate was relatively high, and the subjects came from different social backgrounds and different geographical areas. In addition, the pattern of dietary intake was very similar to that observed in population-based surveys carried out in the Spanish regions included in the present study $^{(58,59)}$.

We conclude that R\&P and especially trans-piceid are common components of the Mediterranean diet. Clearly, wine is the major contributor of $\mathrm{R} \& \mathrm{P}$ in this population $(>98 \%)$; the contribution of non-grape derivatives is lower than $0.01 \%$. This is the first attempt to compile the existing published scientific data on the R\&P content of foods. This database allowed the quantification of intakes that can be used to investigate the role of $\mathrm{R} \& \mathrm{P}$ in health benefits to increase lifespan.

\section{Acknowledgements}

The present study is part of the EPIC-Spain Study. The EPIC Study in Spain has received financial support from the Health Research Fund (FIS, 02/0652) of the Spanish Ministry of 
Health, the ISCIII (RETIC-RD06/0020 and the CIBER in Epidemiology and Public Health) and the Spanish Regional Government of Andalusia, Asturias, Basque Country, Murcia and Navarra and the Catalan Institute of Oncology. Some authors are partners of ECNIS, a network of excellence of the EU 6FP. AGL2006-14228-C03-02/ALI and Program Ingenio CONSOLIDER CSD2007-063 also contributed to the present study. R. Z.-R. was supported by the Departament d'Universitats, Recerca i Societat de la Informació (Catalunya). The authors are not aware of any conflict of interest.

\section{References}

1. Soleas GJ, Diamandis EP \& Goldberg DM (1997) Resveratrol: a molecule whose time has come? And gone? Clin Biochem 30, 91-113.

2. Gonzalez-Barrio R, Beltran D, Cantos E, Gil MI, Espin JC \& Tomas-Barberan FA (2006) Comparison of ozone and UV-C treatments on the postharvest stilbenoid monomer, dimer, and trimer induction in var. 'Superior' white table grapes. J Agric Food Chem 54, 4222-4228.

3. Romero-Perez AI, Lamuela-Raventos RM, Andres-Lacueva C \& Torre-Boronat MC (2001) Method for the quantitative extraction of resveratrol and piceid isomers in grape berry skins. Effect of powdery mildew on the stilbene content. J Agric Food Chem 49, 210-215.

4. Burns J, Yokota T, Ashihara H, Lean ME \& Crozier A (2002) Plant foods and herbal sources of resveratrol. J Agric Food Chem 50, 3337-3340.

5. Rimando AM, Kalt W, Magee JB, Dewey J \& Ballington JR (2004) Resveratrol, pterostilbene, and piceatannol in Vaccinium berries. J Agric Food Chem 52, 4713-4719.

6. Sobolev VS \& Cole RJ (1999) Trans-resveratrol content in commercial peanuts and peanut products. J Agric Food Chem 47, $1435-1439$.

7. Tokusoglu O, Unal MK \& Yemis F (2005) Determination of the phytoalexin resveratrol $\left(3,5,4^{\prime}\right.$-trihydroxystilbene) in peanuts and pistachios by high-performance liquid chromatographic diode array (HPLC-DAD) and gas chromatography-mass spectrometry (GC-MS). J Agric Food Chem 53, 5003-5009.

8. Ragab AS, Van FJ, Jankowski B, Park JH \& Bobzin SC (2006) Detection and quantitation of resveratrol in tomato fruit (Lycopersicon esculentum Mill.). J Agric Food Chem 54, 7175-7179.

9. Cantos E, Espin JC \& Tomas-Barberan FA (2002) Varietal differences among the polyphenol profiles of seven table grape cultivars studied by LC-DAD-MS-MS. J Agric Food Chem 50, 5691-5696.

10. Lamuela-Raventós R, Romero-Pérez A, Waterhouse A \& de la Torre-Boronat M (1995) Direct HPLC analysis of cis- and trans-resveratrol and piceic isomers in Spanish red Vitis vinifera wines. J Agric Food Chem 43, 281-283.

11. Romero Perez AI, Lamuela Raventos RM, Waterhouse AL \& de la Torre Boronat MC (1996) Levels of cis-and trans-resveratrol and their glucosides in white and rosé Vitis vinifera wines from Spain. J Agric Food Chem 44, 2124-2128.

12. Vitrac X, Bornet A, Vanderlinde R, Valls J, Richard T, Delaunay JC, Merillon JM \& Teissedre PL (2005) Determination of stilbenes ( $\delta$-viniferin, trans-astringin, trans-piceid, cis- and trans-resveratrol, $\varepsilon$-viniferin) in Brazilian wines. J Agric Food Chem 53, $5664-5669$.

13. Landrault N, Larronde F, Delaunay J, Castagnino C, Vercauteren J, Mérillon J, Gasc F, Cros G \& Teissedre P (2002) Levels of stilbene oligomers and astilbin in French varietal wines and in grapes during noble rot development. J Agric Food Chem 50, 2046-2052.
14. Delmas D, Lancon A, Colin D, Jannin B \& Latruffe N (2006) Resveratrol as a chemopreventive agent: a promising molecule for fighting cancer. Curr Drug Targets 7, 423-442.

15. Signorelli P \& Ghidoni R (2005) Resveratrol as an anticancer nutrient: molecular basis, open questions and promises. $J$ Nutr Biochem 16, 449-466.

16. Dore $S$ (2005) Unique properties of polyphenol stilbenes in the brain: more than direct antioxidant actions; gene/protein regulatory activity. Neurosignals 14, 61-70.

17. Fremont L (2000) Biological effects of resveratrol. Life Sci 66 , $663-673$

18. Olas B \& Wachowicz B (2005) Resveratrol, a phenolic antioxidant with effects on blood platelet functions. Platelets 16, 251-260.

19. Juan ME, Gonzalez-Pons E, Munuera T, Ballester J, RodriguezGil JE \& Planas JM (2005) trans-Resveratrol, a natural antioxidant from grapes, increases sperm output in healthy rats. $J$ Nutr 135, 757-760.

20. Baur JA \& Sinclair DA (2006) Therapeutic potential of resveratrol: the in vivo evidence. Nat Rev Drug Discov 5, 493-506.

21. Ingram DK, Zhu M, Mamczarz J, Zou S, Lane MA, Roth GS \& deCabo $\mathrm{R}$ (2006) Calorie restriction mimetics: an emerging research field. Aging Cell 5, 97-108.

22. Baur JA, Pearson KJ, Price NL, et al. (2006) Resveratrol improves health and survival of mice on a high-calorie diet. Nature 444, 337-342.

23. Delmas D, Jannin B \& Latruffe N (2005) Resveratrol: preventing properties against vascular alterations and ageing. Mol Nutr Food Res 49, 377-395.

24. Orallo F (2006) Comparative studies of the antioxidant effects of cis- and trans-resveratrol. Curr Med Chem 13, 87-98.

25. Goldberg DM, Yan J \& Soleas GJ (2003) Absorption of three wine-related polyphenols in three different matrices by healthy subjects. Clin Biochem 36, 79-87.

26. Meng X, Maliakal P, Lu H, Lee MJ \& Yang CS (2004) Urinary and plasma levels of resveratrol and quercetin in humans, mice, and rats after ingestion of pure compounds and grape juice. $J$ Agric Food Chem 52, 935-942.

27. Soleas GJ, Yan J \& Goldberg DM (2001) Ultrasensitive assay for three polyphenols (catechin, quercetin and resveratrol) and their conjugates in biological fluids utilizing gas chromatography with mass selective detection. $J$ Chromatogr B Biomed Sci Appl 757, 161-172.

28. Urpi-Sarda M, Jauregui O, Lamuela-Raventos RM, Jaeger W, Miksits M, Covas M \& Andres-Lacueva C (2005) Uptake of diet resveratrol into the human low density lipoprotein. Identification and quantification of resveratrol metabolites by liquid chromatography coupled with tandem mass spectrometry. Anal Chem 77, 3149-3155.

29. Vitaglione P, Sforza S, Galaverna G, Ghidini C, Caporaso N, Vescovi PP, Fogliano V \& Marchelli R (2005) Bioavailability of trans-resveratrol from red wine in humans. Mol Nutr Food Res 49, 495-504.

30. Walle T, Hsieh F, DeLegge MH, Oatis JE \& Walle UK (2004) High absorption but very low bioavailability of oral resveratrol in humans. Drug Metab Dispos 32, 1377-1382.

31. Yu C, Shin YG, Chow A, Li Y, Kosmeder JW, Lee YS, Hirschelman WH, Pezzuto JM, Mehta RG \& van Breemen RB (2002) Human, rat, and mouse metabolism of resveratrol. Pharm Res 19, 1907-1914.

32. Zamora-Ros R, Urpi-Sarda M, Lamuela-Raventos RM, Estruch R, Vazquez-Agell M, Serrano-Martinez M, Jaeger W \& AndresLacueva C (2006) Diagnostic performance of urinary resveratrol metabolites as a biomarker of moderate wine consumption. Clin Chem 52, 1373-1380.

33. Koga T \& Meydani M (2001) Effect of plasma metabolites of (+)-catechin and quercetin on monocyte adhesion to human aortic endothelial cells. Am J Clin Nutr 73, 941-948. 
34. Moon JH, Tsushida T, Nakahara K \& Terao J (2001) Identification of quercetin 3-O- $\beta$-D-glucuronide as an antioxidative metabolite in rat plasma after oral administration of quercetin. Free Radic Biol Med 30, 1274-1285.

35. Boocock DJ, Patel KR, Faust GES, Normolle DP, Marczylo TH, Crowell JA, Brenner DE, Booth TD, Gescher A \& Steward WP (2007) Quantitation of trans-resveratrol and detection of its metabolites in human plasma and urine by high performance liquid chromatography. $J$ Chromatogr $B$ Analyt Technol Biomed Life Sci 848, 182-187.

36. Gonzalez CA, Navarro C, Martinez C, et al. (2004) The European Prospective Investigation into Cancer and Nutrition (EPIC) (article in Spanish). Rev Esp Salud Publica 78, 167-176.

37. Anonymous (1997) Relative validity and reproducibility of a diet history questionnaire in Spain. I. Foods. EPIC Group of Spain. European Prospective Investigation into Cancer and Nutrition. Int J Epidemiol 26, Suppl. 1, S91-S99.

38. Anonymous (1997) Relative validity and reproducibility of a diet history questionnaire in Spain. II. Nutrients. EPIC Group of Spain. European Prospective Investigation into Cancer and Nutrition. Int J Epidemiol 26, Suppl. 1, S100-S109.

39. Moller A, Rhodes M, Preece R, Walker A, Atkins D, Bailey G, van Klaveren J \& Vittozzi L (1998) Proposal for the structure and organisation of a future European database Report no. 3. EU-AIR NETTOX (1995-1997). http://www.foodcomp.dk/ basis/ (accessed 15 December 2006).

40. Trela BC \& Waterhouse AL (1996) Resveratrol: isomeric molar absorptivities and stability. J Agric Food Chem 44, 1253-1257.

41. Ministerio de Agricultura Pesca y Alimentación (2004) La Alimentación en España. 2003 (Food in Spain.2003). Madrid: Ministerio de Agricultura Pesca y Alimentación.

42. Instituto Nacional de Estadística (2005) Instituto Nacional de Estadística (National Statistics Institute) http://www.ine.es (accessed 15 December 2006).

43. Flanders WD, DerSimonian R \& Freedman DS (1992) Interpretation of linear regression models that include transformations or interaction terms. Ann Epidemiol 2, 735-744.

44. R Development Core Team (2006) A Language and Environment for Statistical Computing. Vienna, Austria: R Foundation for Statistical Computing.

45. Alarcón de la Lastra C \& Villegas I (2005) Resveratrol as an anti-inflammatory and anti-aging agent: mechanisms and clinical implications. Mol Nutr Food Res 49, 405-430.

46. Moreno-Labanda J, Mallavia R, Pérez-Fons L, Lizama V, Saura D \& Micol V (2004) Determination of piceid and resveratrol in Spanish wines deriving from Monastrell (Vitis vinifera $\mathrm{L}$.) grape variety. J Agric Food Chem 52, 5396-5403.

47. Lee S, Lee S, Kim M, Chun J, Cheong Y \& Lee J (2004) Analysis of trans-resveratrol in peanuts and peanut butters consumed in Korea. Food Res Intern 37, 247-251.

48. Nicoletti I, De Rossi A, Giovinazzo G \& Corradini D (2007) Identification and quantification of stilbenes in fruits of transgenic tomato plants (Lycopersicon esculentum Mill.) by reversed phase HPLC with photodiode array and mass spectrometry detection. J Agric Food Chem 55, 3304-3311.

49. Sieri S, Agudo A, Kesse E, et al. (2002) Patterns of alcohol consumption in 10 European countries participating in the European Prospective Investigation into Cancer and Nutrition (EPIC) project. Public Health Nutr 5, 1287-1296.

50. Guallar-Castillón P, Rodríguez-Artalejo F, Díez-Gañan L, Banegas Banegas JR, Lafuente Urdionguio P \& Herruzo Cabrera R (2001) Consumption of alcoholic beverages and subjective health in Spain. J Epidemiol Community Health 55, 648-652.

51. Marques-Vidal P \& Dias CM (2005) Trends and determinants of alcohol consumption in Portugal: results from the national health surveys 1995 to 1996 and 1998 to 1999. Alcohol Clin Exp Res 29, 89-97.
52. Levi F, Pasche C, Lucchini F, Ghidoni R, Ferraroni $\mathrm{M} \&$ La Vecchia C (2005) Resveratrol and breast cancer risk. Eur J Cancer Prev 14, 139-142.

53. Kuhnle G, Spencer JPE, Chowrimootoo G, Schroeter H, Debnam ES, Srai SKS, Rice-Evans C \& Hahn U (2000) Resveratrol is absorbed in the small intestine as resveratrol glucuronide. Biochem Biophys Res Commun 272, 212-217.

54. Henry-Vitrac C, Desmouliere A, Girand D, Merillon JM \& Krisa S (2006) Transport, deglycosilation, and metabolism of trans-piceid by small intestinal epithelial cells. Eur J Nutr 45, 376-382.

55. Potischman N (2003) Biologic and methodologic issues for nutritional biomarkers. J Nutr 133, Suppl. 3, 875S-880S.

56. Kelemen LE (2006) Food frequency questionnaires: not irrelevant yet. Cancer Epidemiol Biomarkers Prev 15, 1054.

57. Szmitko PE \& Verma S (2005) Cardiology patient pages. Red wine and your heart. Circulation 111, e10-e11.

58. Aranceta J, Perez C, Eguileor I, Gonzalez de Goldeano J, Mataix J \& Saez de Burauga J (1990) Nutritional Survey. Technical Documents of Public Health, ser. A, no. 9. Vitoria, Spain: Government of the Basque Country.

59. Mataix J, Llopis J, Martinez de Victoria E, Montellano MA, Lopez M \& Aranda P (1999) Evaluation of the Nutritional Status in the Autonomous Community of Andalucia. Granada, Spain: Public Health Service and Institute of Nutrition and Food Technology of the University of Granada.

60. Goldberg DM, Karumanchiri A, Ng E, Yan J, Diamandis EP \& Soleas GJ (1995) Direct gas-chromatographic mass-spectrometric method to assay cis-resveratrol in wines - preliminary survey of its concentration in commercial wines. J Agric Food Chem 43, 1245-1250.

61. Rodriguez-Delgado M, González G, Pérez-Trujillo J \& GarcíaMontelongo F (2002) Trans-resveratrol in wines from the Canary Islands (Spain). Analysis by high performance liquid chromatography. Food Chem 76, 371-375.

62. Álvarez-Sala L, Slowing-Barrillas K, Gómez-Serranillos P, Torres-Segovia F, Valderrama-Rojas M \& Millán-Núñez J (2000) Variabilidad del contenido de polifenoles de distintos tipos de vino y su potencial aplicación al conocimiento de sus efectos biológicos (Variability of the content of polyphenols of different types from wine and potential application from the knowledge of their biological effects). Med Clin (Barc) 114, 331-332.

63. Martinez-Ortega MV, Carcia-Parrilla MC \& Troncoso AM (2000) Resveratrol content in wines and musts from the south of Spain. Nahrung 44, 253-256.

64. Andres-Lacueva C, Ibern-Gomez M, Lamuela-Raventos RM, Buxaderas S \& de la Torre-Boronat M (2002) Cinnamates and resveratrol content for sparkling wine characterization. Am J Enol Vitic 53, 147-150.

65. Pozo-Bayon MA, Hernandez MT, Martin-Alvarez PJ \& Polo MC (2003) Study of low molecular weight phenolic compounds during the aging of sparkling wines manufactured with red and white grape varieties. J Agric Food Chem 51, 2089-2095.

66. de Lima M, Waffo-Téguo P, Teissedre P, Pujolas A, Vercauteren J, Cabanis J \& Mérillon J (1999) Determination of stilbenes (trans-astringin, cis- and trans-piceid, and cis- and trans-resveratrol) in Portuguese wines. J Agric Food Chem 47, 2666-2670.

67. Goldberg DM, Yan J, Ng E, Diamandis EP, Karumanchiri A, Soleas G \& Waterhouse AL (1995) A global survey of transresveratrol concentrations in commercial wines. Am J Enol Vitic 46, 159-165.

68. Cantos E, Espin JC \& Tomas-Barberan FA (2002) Postharvest stilbene-enrichment of red and white table grape varieties using UV-C irradiation pulses. J Agric Food Chem 50, 6322-6329.

69. Cantos E, Tomas-Barberan FA, Martinez A \& Espin JC (2003) Differential stilbene induction susceptibility of seven red wine grape varieties upon post-harvest UV-C irradiation. Eur Food Res Technol 217, 253-258. 
70. Vinas P, Lopez-Erroz C, Marin-Hernandez JJ \& HernandezCordoba M (2000) Determination of phenols in wines by liquid chromatography with photodiode array and fluorescence detection. J Chromatogr A 871, 85-93.

71. Roldan A, Palacios V, Caro I \& Perez L (2003) Resveratrol content of Palomino fino grapes: influence of vintage and fungal infection. J Agric Food Chem 51, 1464-1468.

72. Romero-Perez AI, Ibern-Gomez M, Lamuela-Raventos RM \& Torre-Boronat MC (1999) Piceid, the major resveratrol derivative in grape juices. J Agric Food Chem 47, 1533-1536.
73. Ibern-Gomez M, Roig-Pérez S, Lamuela-Raventos RM \& de la Torre-Boronat M (2000) Resveratrol and piceid levels in natural and blended peanut butters. J Agric Food Chem 48, $6352-6354$.

74. Zhang K \& Zuo YG (2004) GC-MS determination of flavonoids and phenolic and benzoic acids in human plasma after consumption of cranberry juice. J Agric Food Chem 52, 222-227.

75. Lyons MM, Yu C, Toma RB, Cho SY, Reiboldt W, Lee J \& van Breemen RB (2003) Resveratrol in raw and baked blueberries and bilberries. J Agric Food Chem 51, 5867-5870. 